\title{
Author bios
}

Georg Albert is a tenured academic assistant for linguistics in the Department of German Language and Literature at the University of Koblenz-Landau, Germany. In 2012, he completed a $\mathrm{PhD}$ at the University of Mannheim with a thesis examining innovative writing and syntactic variation in online chats and discussion boards. His research interests include semiotics, multimodality and media theory, interactional linguistics, sociolinguistics, language change and variation.

Dorottya Cserző completed her PhD at the Centre for Language and Communication at Cardiff University, Wales, UK. Her research project explored the domestic use of videochat through the analysis of video recordings and interviews. She is co-editor of Downscaling Culture: Revisiting Intercultural Communication (2016, Cambridge Scholars).

Francesca Frontini is Associate Professor ("maître de conférences") in Computational Linguistics at the Paul-Valéry University of Montpellier in France where she is also a member of the Laboratoire Praxiling. She earned a PhD from the University of Pavia, Italy, with a thesis in corpus linguistics and later worked at the Institute for Computational Linguistics in Pisa. Her research interests lie in natural language processing, corpus linguistics, computational lexicography, digital humanities, as well as language resources, creation, standardisation and preservation.

Vanessa Jaroski completed her PhD in language and communication at the University of Bern, Switzerland. As part of a larger SNSF-funded project (What's up, Switzerland?), her thesis examined the representation of digital media in international news media discourse from a multimodal and multilingual perspective. In this work, she explored the intersection of language, media and semiotic ideologies with a particular view to women and girls. This project also centered on the development of an open-access, participatory archive, the Digital Discourse Database (www.digitaldiscoursedatabase.org).

Rodney H. Jones is Professor of Sociolinguistics and Head of the Department of English Language and Applied Linguistics at the University of Reading, England, UK. He has published widely in the areas of digital literacies, mediated discourse analysis and health communication.

Sirpa Leppänen is a Professor in the Department of Language and Communication Studies at the University of Jyväskylä, Finland. Drawing on insights provided by sociolinguistics, discourse studies, the study of multimodality and cultural studies, she has investigated a range of informal and interest-driven social media discourses. She has published widely on (1) semiotic (linguistic, discursive, visual, auditory) diversity as a resource for interaction and cultural production in translocal social media, (2) identifications and communality online, and (3) transgression as a means for cultural production, digital work and political activism.

Katharina Lobinger is Assistant Professor for Online Communication at the Institute of Digital Technologies for Communication at USI (Università della Svizzera italiana), Switzerland. Her main research interests include networked photography, online communication, digital (visual) culture, ethics for the digital age, and creative and visual research methods. She is principal investigator of the project "Visualized relationships - functions and problems" funded by the Swiss National Science Foundation. She is currently chair of the visual communication division of the German Communication Association. 
Konstanze Marx is Full Professor in German Linguistics at the Greifwald University, Germany. Before she was also Research Fellow in the Department of Pragmatics at the Leibniz Institute of German Language and the Technical University of Berlin. She studied German, Phonetics, Media Science and Educational Science at the University of Jena and completed her Habilitation on cyberbullying at the Technical University of Berlin. Her research focuses on internet linguistics, language and emotion, and medialinguistic prevention. She is co-founder of Journal für Medienlinguistik/Journal for Media Linguistics.

Dorothee Meer is academic counsellor in Applied Linguistics and German Linguistics and Didactics at the Ruhr-University Bochum, Germany. Her publications include monographs and chapters on discourse analysis and academic talk, as well as chapters on multimodality and digital media.

Rachel Panckhurst is Associate Professor in Computational Linguistics at Paul-Valéry University in Montpellier, France, where she is also member of the Dipralang laboratory. Her research interests include mediated digital discourse, mobile technology and innovative eLearning practices. She directed the sud4science project (sud4science.org); was director of Montpellier University's METICE Centre for open, distance and digital education; and has authored or edited over 190 publications, including three books.

Jana Pflaeging is a researcher in English and applied linguistics in the Department of English and American Studies at Salzburg University, Austria. She is currently pursuing a binational PhD at Salzburg University, Austria, and Halle-Wittenberg University, Germany. Her research interests are in multimodal genre studies and text/discourse linguistics. Trained in English linguistics and fine arts, she explores the synergies between both fields when creating visualizations of linguistic and multimodal theories, methods, and data.

Lara Portmann is a doctoral candidate at the University of Bern, Switzerland. Her current project focuses on UX writing as a site for studying audience design, 'digital pragmatics' and the language-ideological implications of wordsmiths. As with the chapter here, she is also interested in social semiotic approaches to digital media representations; this work has already appeared in major international venues such as New Media \& Society.

Axel Schmidt is Research Fellow in the Department of Pragmatics at the Leibniz Institute of German Language and Professor in the Media and Communication Department at the University of Mannheim, Germany. He studied Sociology and Educational Science in Frankfurt am Main University, completed a PhD at Koblenz-Landau University on peer-group communication, and then a post-doctoral (Habilitation) project at the University of Basel (Switzerland) on staging in reality television. His research focuses on theatre, television, video games as well as on interaction analysis and multimodal video analysis. Currently he is investigating interactions in media productions.

Katharina Staubach is a postgraduate researcher at Ruhr-University Bochum, Germany. She is currently working on the GramKidSII project (Grammatische Kenntnisse in der Sekundarstufe II) directed by Professor Björn Rothstein. Her publications to date focus on issues of multimodality and digital media.

Hartmut Stöckl is Full Professor of English and Applied Linguistics in the Department of English and American Studies at Salzburg University, Austria. His main research areas are in 
semiotics, media/text linguistics/stylistics, pragmatics and linguistic multimodality research. $\mathrm{He}$ is particularly interested in the linkage of language and image in modern media, typography and an aesthetic appreciation of advertising. A volume on 'shifts towards image-centricity in contemporary multimodal practices' with Routledge/New York (2019) is his most recent coedited book.

Crispin Thurlow is Professor of language and communication based in the Department of English at the University of Bern, Switzerland. His research examines the social semiotics of difference and inequality in contemporary life, particularly in the contexts of global mobilities and digital media. His more recent publications include Elite Discourse: The Rhetorics of Status, Privilege and Power (2018, Routledge) and The Business of Words: Wordsmiths, Linguists and Other Language Workers (2020, Routledge).

Rebecca Venema is doctoral candidate and research/teaching assistant at the Institute of Digital Technologies for Communication at USI (Università della Svizzera italiana), Switzerland. From 2013 until 2017 she was a research associate at the Centre for Media, Communication and Information Research (ZeMKI) at the University of Bremen. Her research interests include (visual) networked everyday communication, norms and ethics of communication, ethics for the digital age, methods of repertoire-oriented cross-media research, and research ethics. 
